\title{
High-Sulfurous Argentinian Asphaltites and Their Thermal Liquefaction Products
}

\author{
V. Savel'ev', A. Golovko', L. Gorbunova', V. Kamyanov' and C. Galvalizi² \\ 1 Institute of Petroleum Chemistry of Siberian Branch of Russian Academy of Sciences, 3, Academichesky av., 63402 1, Tomsk - Russia \\ 2 Scientific Foundation of South Pole, Lima 131, 3F C1073AAC, Buenos Aires - Argentina \\ e-mail: savel@ipc.tsc.ru
}

\begin{abstract}
Résumé - Asphaltites d'Argentine à forte teneur en soufre et les produits de leur liquéfaction thermique - Ce travail présente les résultats d'une étude approfondie de la nature chimique des asphaltites des gisements Rafaelita et Toribia (des provinces Mendoza et Neuquéen en Argentine) ainsi que des propositions pour le traitement de ces charges. La composition et les particularités structurales des composants maltènes, asphalténiques et hydrocarbonés plus légers de ces composés, proches du charbon, ont été étudiées. Des expériences en laboratoire sur la liquéfaction thermique des asphaltites ont été réalisées, incluant : 1) une pyrolyse à températures croissantes jusqu'à $600^{\circ} \mathrm{C}$;2) une conversion thermique en condition de température programmée allant de 25 jusqu'à 350 ou $450^{\circ} \mathrm{C}$ en fixant une rampe de montée en température de $5^{\circ} \mathrm{C}$ par minute et avec récupération des produits de réaction dans un gazole de distillation directe ; 3) un traitement thermique des échantillons étudiés sous conditions stationnaires (à $350{ }^{\circ} \mathrm{C}$ pendant une heure dans l'eau, la tétraline ou le n-décane) ; et finalement 4) une transformation thermique des échantillons d'asphaltites sous différentes atmosphères (injection en continu dans le réacteur d'eau ou de décane, la température variant de $25^{\circ} \mathrm{C}$ jusqu'à $500^{\circ} \mathrm{C}$, avec prises d'essais à différents niveaux de température). Le rendement le plus élevé en produits de conversion a été obtenu lorsque la conversion thermique a été réalisée en milieu hydrocarboné à des températures pas plus faibles que 400$450^{\circ} \mathrm{C}$, en prélevant en continu les produits formés pendant la réaction. Le rendement en hydrocarbures légers a atteint $25 \%$ poids de la quantité organique d'asphaltite initiale lorsque le n-décane a constitué le milieu réactionnel, et a pu croître jusqu'à $70 \%$ poids en substituant ce solvant par une coupe gazole.
\end{abstract}

\begin{abstract}
High-Sulfurous Argentinian Asphaltites and Their Thermal Liquefaction Products - The results of profound chemical studies of asphaltites from the Rafaelita and Toribia fields (Mendosa and Neuquén provinces, Argentina) and prospects for their processing are presented. The composition and structural features of maltenic, asphaltene-carbenic and carboid components of these natural coal-like substances were investigated. Laboratory experiments on thermal liquefaction of asphaltites were performed, including: 1) destructive distillation (pyrolysis) at temperatures gradually rising up to $600^{\circ} \mathrm{C}$; 2) thermal destruction under conditions of programmed temperature increase from 25 up to 350 or $450^{\circ} \mathrm{C}$ with a rate of $5^{\circ} \mathrm{C} / \mathrm{min}$ and with simultaneous dilution of reaction products by straight-run diesel petroleum distillate; 3) thermal treatment of the studied sample under stationary conditions (at $350^{\circ} \mathrm{C}$ for one hour in water, tetraline or n-decane); and 4) thermal destruction of asphaltite samples under flow conditions (continuous ablution of reactor with water or decane, temperature rising from 25 up to $500^{\circ} \mathrm{C}$, with periodical sampling at different temperature levels). The largest yields of liquid fuels were obtained when the thermal destruction process was performed in hydrocarbon medium at temperatures not lower than $400-450^{\circ} \mathrm{C}$, with continuous removal of products from the reaction zone. The yield of desirable hydrocarbon products reached $25 \mathrm{wt} . \%$ of asphaltite organic mass, when decane served as reaction medium, and could be increased up to $70 \mathrm{wt}$.\% by substituting this solvent with real petroleum (diesel) distillate.
\end{abstract}




\section{INTRODUCTION}

New methods of obtaining profound information about chemical composition and structural features of mineral components were discovered in the second half of the last century and caused a significant impulse in investigations of different natural hydrocarbon systems: gases, gas condensates, crude oils, bitumens and coals [1-4]. However, such specific kinds of native combustible fossils as asphaltites were rarely studied (combustible organic rock formed by direct degraded oil or accumulation of plant materials; including coal and peat). It is obvious that it is impossible to develop rational ways of processing these materials into more valuable liquid hydrocarbon fuels without sufficient information about their chemical nature.

The aim of this work is to study the effect of different thermolysis conditions on the degree of asphaltite liquation and final product composition.

\section{EXPERIMENTAL}

\subsection{Analytical Techniques}

Asphaltites from the Rafaelita (R-03) and Toribia (T-05) fields located in the Andes foothills in Mendosa and Neuken provinces (Argentina) were used in this study. The samples were obtained from Upper Cretaceous asphaltite-bearing sediments that outcrop on the earth's surface.

These samples are typical orto-asphaltites according to the international method of classification [1]; they have solid fragile substances and a black color. These asphaltites outwardly resemble hardened oil and have glass-like brilliance upon fresh fracture. The ash content of samples is about 2-3 wt. $\%$, density $1100 \mathrm{~kg} / \mathrm{m}^{3}$, softening point $+250^{\circ} \mathrm{C}$ and zero penetration at $25^{\circ} \mathrm{C} .99 .2 \mathrm{wt} . \%$ of these substances dissolve in $\mathrm{CS}_{2}$; in other words, the content of mineral matter is no more than $0.8 \mathrm{wt} . \%$.

An experiment, cumulated while working with crude oils and brown coals, was widely used in our study [5-7].

Samples of initial solid asphaltites were ground into particles of $0.2 \mathrm{~mm}$ mean size and placed into cartridges of filter paper for separation in a Soxhlet apparatus. The maltenic fraction of the raw material was eluted with n-hexane. Isolated maltenes were placed on ASK silica gel. This mixture was set in the extractor again where hydrocarbons and resin compounds were desorbed with hexane and chloroform, respectively.

Solids, retained in cartridges after separation of maltenes, were extracted exhaustively with chloroform to obtain the mixture of asphaltenes and carbenes ( $\mathrm{A}+\mathrm{K}$ fraction). These components were not divided additionally and were analyzed as single objects.
The insoluble-in-chloroform solid residual mixture of carboids and ash was not analyzed at all.

$\mathrm{C}, \mathrm{H}, \mathrm{N}$ and $\mathrm{O}$ contents were determined using a Karlo Erba automatic analyzer, model 1106.

Average molecular weights were measured by cryoscopy in naphthalene using a "Krion" instrument engineered in the Tomsk Institute of Petroleum Chemistry.

Metal contents in asphaltites were detected using an X-ray fluorescent analyzer.

IR spectra of powdered solid substances were obtained in tablets of $\mathrm{KBr}$; spectra of isolated fractions - in chloroform solutions with the use of a M-80 spectrometer.

1HNMR spectra were recorded on an "AVANCE" AV300 Furier-spectrometer (solvent - deuterochloroform, internal standard - hexamethyldisiloxane) with $1 \mathrm{wt} . \%$ concentration of analyzed substance in solution.

Experimental data on the molecular weight, elemental and functional composition of substances and proton distribution between different fragments of molecules were used to calculate structural-group parameters of asphaltite fractions with the use of procedures described in former publications [610]. The designations of these parameters are identical to the designations used in works [6-10] and will be explained additionally where needed.

Processes of thermal and oxidation decomposition, which occur in asphaltites while heating in inert medium or in air, were studied by thermogravimetric and differential thermal methods. Experiments on asphaltite decomposition were done using a Paulik-Paulik-Erdey Q-1000 instrument (MOM firm, Hungary).

$50 \mathrm{mg}$ of asphaltite were placed as a thin layer in a platinum crucible and heated up to $1000^{\circ} \mathrm{C}$ with a rate of $10^{\circ} \mathrm{C} / \mathrm{min}$. Transformations of substances were studied in two different stationary media of helium and air in covered crucibles. As well as this, destruction of asphaltites in helium and air gas flow $\left(500 \mathrm{~cm}^{3} / \mathrm{min}\right)$ was carried out in plate crucibles.

The principal macro-structural features of particles that form in asphaltites were established by means of X-ray diffraction analysis (XDA). Curves of X-ray diffraction on asphaltite powders were recorded using a "Dron-3" instrument (Russia) in the angle region of $2 \theta=3-60^{\circ}$ (radiation of $\mathrm{Cu} \mathrm{K \alpha}$, wavelength $\lambda=1.5418 \AA$ ) in cuvettes of $25 \mathrm{~mm}$ in diameter and $2 \mathrm{~mm}$ in thickness. The curves obtained were processed using techniques described in [10].

\subsection{Asphaltite Liquefaction Methods}

The simplest method of thermal destruction of asphaltite was performed by Argentinian scientists in dry distillation (pyrolysis) of R-03 samples under conditions of programmed increasing temperature from 20 up to $600^{\circ} \mathrm{C}$ with a rate of $10^{\circ} \mathrm{C} / \mathrm{min}$. 
Another liquefaction technique in stationary conditions was approved when separate portions of R-03 and T-05 asphaltites $(4 \mathrm{~g})$ were fed into a micro-autoclave with addition of $15 \mathrm{~cm}^{3}$ of solvent (n-decane, tetraline or water). The reactor was heated up to $350^{\circ} \mathrm{C}$ at a constant rate of $10^{\circ} \mathrm{C} / \mathrm{min}$ and kept at $350^{\circ} \mathrm{C}$ for an hour. Then the reactor was cooled down rapidly to $22^{\circ} \mathrm{C}$ in water flow and unloaded.

Solid residues, separated from the liquid phase by filtration, were washed thoroughly with chloroform, dried and weighed. The obtained solution was joined with filtrate. The solvent used for filling the reactor and chloroform was distilled.

Also, to enhance the yield of liquid products in the process of R-03 liquation, the hematite $\left(\mathrm{Fe}_{2} \mathrm{O}_{3}\right)$ [11] was added in amounts of $0.2 \mathrm{wt} . \%$.

With a view to studying decomposition of asphaltites in flow conditions $4 \mathrm{~g}$ of powered material were fed into a tube reactor washed continuously by water [12] or organic solvent (decane) [13] with a volume rate of $400 \mathrm{~cm}^{3} /$ hour. The rate of temperature increase was $10^{\circ} \mathrm{C} / \mathrm{min}$ from $20^{\circ} \mathrm{C}$ to $500^{\circ} \mathrm{C}$. The pressure in the reactor was $150 \mathrm{~kg} / \mathrm{cm}^{2}$ to prevent solvent evaporation. When reactor solvent was cooled in water it was cooled down to $22^{\circ} \mathrm{C}$. Samples were gathered for 50 or $100^{\circ} \mathrm{C}$ intervals of temperature. The total degree of asphaltite conversion was estimated as the difference in masses of the organic material fed into the reactor initially, and the residue remaining in it after the experiment.

\section{RESULTS AND DISCUSSION}

\subsection{Substantial Composition of Asphaltites}

Asphaltites R-03 and T-05 have different material compositions (Table 1). Asphaltenes and carbenes ( $\mathrm{A}+\mathrm{K}$ fraction) form about $57 \mathrm{wt} . \%$ of organic mass in R-03 samples. The quantities of hexane-soluble heteroorganic components (resins) and carboids, insoluble in any approved solvents except carbon disulfide, are approximately the same (19-20 wt.\%). Hydrocarbons (oily fractions) present only $4.2 \mathrm{wt} . \%$.

On the contrary, carboids are predominant (64 wt.\% of OMA) in Toribia asphaltite (T-05 sample). Concentrations of $(\mathrm{A}+\mathrm{K})$ and resin components (about $31 \%$ and $5.2 \%$, respectively) are considerably smaller. Hydrocarbons were not found in this asphaltite at all. When solvent was distilled off from hexane eluate only bright yellow wellformed rhombic crystals of sulfur were obtained (1.8 wt.\% of OMA).
TABLE 1

Chemical compositions of asphaltites

\begin{tabular}{l|c|c}
\hline \multirow{2}{*}{ Indices } & \multicolumn{2}{c}{ Values for asphaltite } \\
\cline { 2 - 3 } & R-03 & T-05 \\
\hline Content, wt.\% on organic mass of asphaltite (OMA): & & \\
Oily fraction & 4.2 & 0.0 \\
Resins & 18.6 & 5.2 \\
Asphaltenes+carbenes & 56.8 & 30.8 \\
\hline Carboids & 20.4 & 64.0 \\
\hline Elemental composition, wt.\% on OMA: & & \\
Carbon & 82.52 & 78.23 \\
Hydrogen & 8.07 & 8.32 \\
Nitrogen & 1.09 & 1.31 \\
Sulfur & 4.07 & 7.62 \\
Oxygen & 4.04 & 4.18 \\
Content of metals, wt.\% on total asphaltite: & & \\
\hline Vanadium & 0.170 & 0.290 \\
Nickel & 0.034 & 0.048 \\
Iron & 0.038 & 0.056 \\
\hline
\end{tabular}

Both asphaltite samples were rich in sulfur; $4.07 \mathrm{wt} . \%$ for R-03 and 7.62 wt.\% for T-05. It is obvious that almost all $\mathrm{S}$-atoms in R-03 are in organic compounds and, possibly, in mineral sulfides. As for T-05, three-quarters of S-atoms (excepting the amount of elemental sulfur) are represented in these substances. The absorption band by $1250 \mathrm{~cm}^{-1}(\mathrm{C}=\mathrm{S})$ also implies the presence of organic sulfur compounds in asphaltites [14].

The presence of mineral sulfides is supported by the fact that asphaltites contain vanadium, iron and nickel. The inorganic sulfides must be accumulated in insoluble solids in chloroform products of separation. Oxygen concentration in asphaltites is also substantial (about 4 wt.\%). O-atoms are also contained in organic parts of asphaltites and, probably, in metal oxides. Nitrogen content in asphaltites is considerably lower (1.1-1.3 wt.\%).

\subsubsection{Structural Features of Asphaltites and their Isolated Fractions}

Bands of valence vibrations $\left(2940,2970 \mathrm{~cm}^{-1}\right)$ of asymmetrical stretching in $\mathrm{C}-\mathrm{H}$ bonds of methyl groups, deformation vibrations $\left(1385,1470 \mathrm{~cm}^{-1}\right)$ of $\mathrm{C}-\mathrm{H}$ bonds, and symmetrical bending of the methyl $\mathrm{C}-\mathrm{H}$ bond are the most intensive in IR spectrums (Fig. 1). Full-symmetric vibrations of $\mathrm{C}=\mathrm{C}$ aromatic rings $\left(1600 \mathrm{~cm}^{-1}\right)$ are intensive too. The band (on the right from $3040 \mathrm{~cm}^{-1}$ ) with an intense maximum at $2970 \mathrm{~cm}^{-1}$ is caused by valence vibrations of the same bonds: aromatic $\mathrm{C}-\mathrm{H}$ stretching. The sharp band at $1700 \mathrm{~cm}^{-1}$ indicates the presence of carbonyl-containing substances: $\mathrm{C}=\mathrm{O}$ stretching.

As was observed for typical oil asphaltenes [6,7], the diffraction X-ray scattering curve of asphaltite (Fig. 2) contains bands in the following angle intervals: $2 \theta=3-13^{\circ}$ 


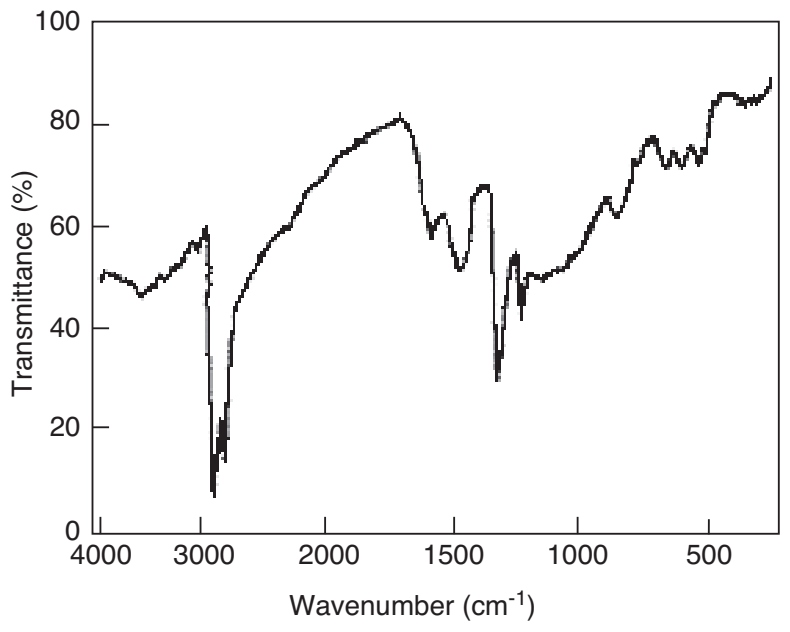

Figure 1

IR spectrum of asphaltite from the Rafaelita field.

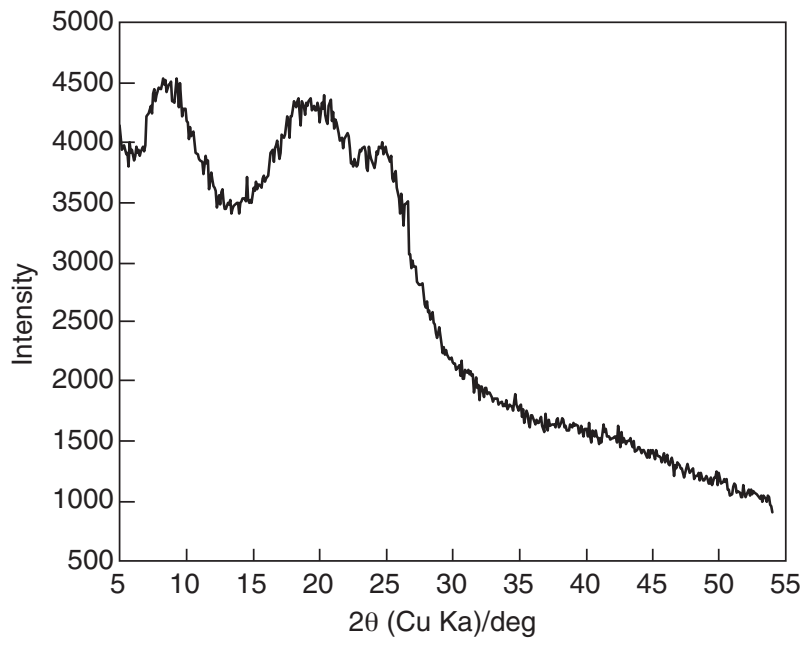

Figure 2

The curve of X-ray diffraction for the asphaltite of the Rafaelita field. (diffraction on macro-particles); $2 \theta=14-22^{\circ}(\gamma$-band, diffraction on spatially indigested atoms of carbon and heteroelements in molecular fragments that frame batch nuclei); $2 \theta=$ $23-28^{\circ}$ (reflection from (002) planes in laminated clusters); $2 \theta=37-47^{\circ}$ (reflection from (10) planes in batches).

The obtained XDA data were used to evaluate macrostructural characteristics of asphaltites. According to average values of macro-structural characteristics of prototurbostrate, i.e. imperfectly built, laminated clusters, that were calculated by methods described in $[6,7,20]$, solid asphaltites have particles formed by $M=4.4$ layers of flat aromatic sheets. The average distance $\left(d_{m}\right)$ between these sheets is $3.56 \AA$.

Total batch thickness across layers is $L_{c}=12.1-12.2 \AA$. $\mathrm{C}$-atoms in substitutes, that frame aromatic nuclei of neighboring layers $\left(d_{\gamma}=5.67 \AA\right.$ and $5.84 \AA$ in samples R-03 and $\mathrm{T}-05$, respectively) are located farther one from another. It is also obvious that batch particles in T-05 samples are more friable than in R-03 ones.

The calculated average diameters of flat sheets in batch layers of asphaltites are $L_{a}=13.6-14.0 \AA$. Dimensions of these nuclei are approximately smaller on $3 \AA$ (i.e. the length of the chemical bond of carbon atoms located at $\alpha$-positions to aromatic nuclei in the same plane [8]); hence, equal to 10.6-11.0 A. Such dimensions are characteristic of condensed tetra- and pentacyclic aromatic nuclei [15-19].

Our calculations showed that $F_{\mathrm{a}}=39-40 \%$ of all $\mathrm{C}$-atoms or $\varphi_{\mathrm{a}}=52-53 \%$ of aromatic nuclei are organized in laminated clustered structures. In other words, about $60 \%$ of all carbon atoms form saturated frames of asphaltite batches.
The first aforementioned band on the diffraction curve of asphaltites (maximum at $2 \theta \approx 8.0^{\circ}$ ) is caused by particles, according to the Wulf-Bragg formula [17], with average diameter of about $12.3 \AA$. That figure conforms to dimensions $L_{c}$ and $L_{a}$ of clusters detected from parameters of other spectral bands.

All geometric dimensions of macroparticles formed in asphaltites as well as the number of $\mathrm{C}$-atoms in these macroparticles are similar to corresponding parameters of high-molecular oil compounds (resins and asphaltenes) $[6,7]$.

\subsubsection{Studies on Thermal and Thermal-Oxidation Transformations of Asphaltites}

Some examples of integral (TG) and differential ( $d$ TG) curves for R-03 asphaltite as well as its differential thermal analysis ( $d$ TA) curves are given in Figures 3 and 4 .

Heating was conducted in stationary inert medium and in helium flow (with simultaneous removal of volatile products). The first signs of molecular destruction (loss in mass) appear on TG curves at temperatures of $70-80^{\circ} \mathrm{C}$ (Figs. 3a, 4a).

This temperature is insufficient to rupture $\mathrm{C}-\mathrm{H}$ and $\mathrm{C}-\mathrm{C}$ bonds, so thermal decomposition of asphaltites begins, certainly, with breaking less stable $\mathrm{C}-\mathrm{S}$ bonds. These reactions accelerate with increase in temperature but make a comparatively small contribution to total mass losses. When the temperature reaches $310-320^{\circ} \mathrm{C}$, intense cracking reactions of saturated hydrocarbon fragments start. 

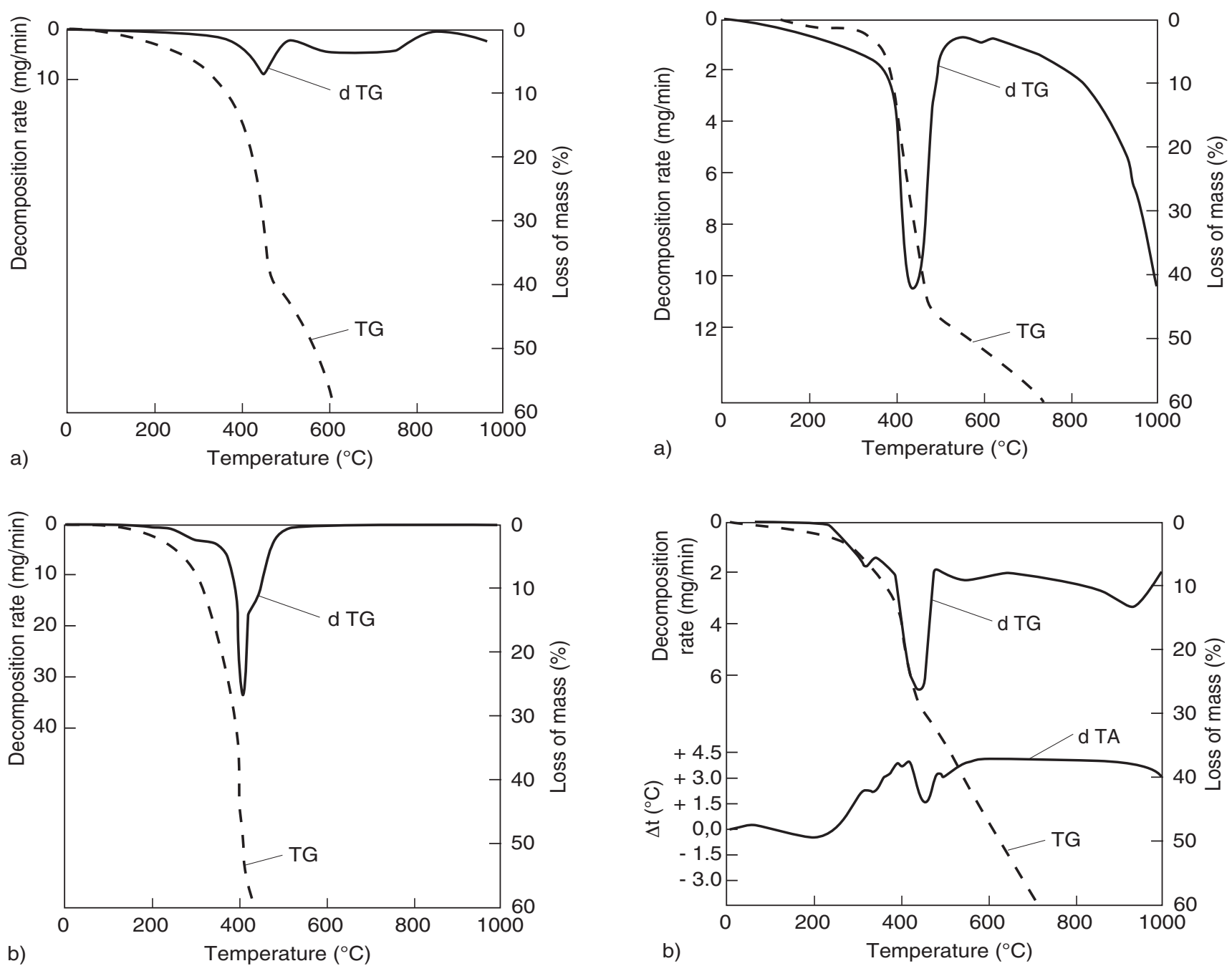

Figure 3

Results of thermogravimetric analysis of Rafaelita asphaltite in a flow of air (a) or helium (b).

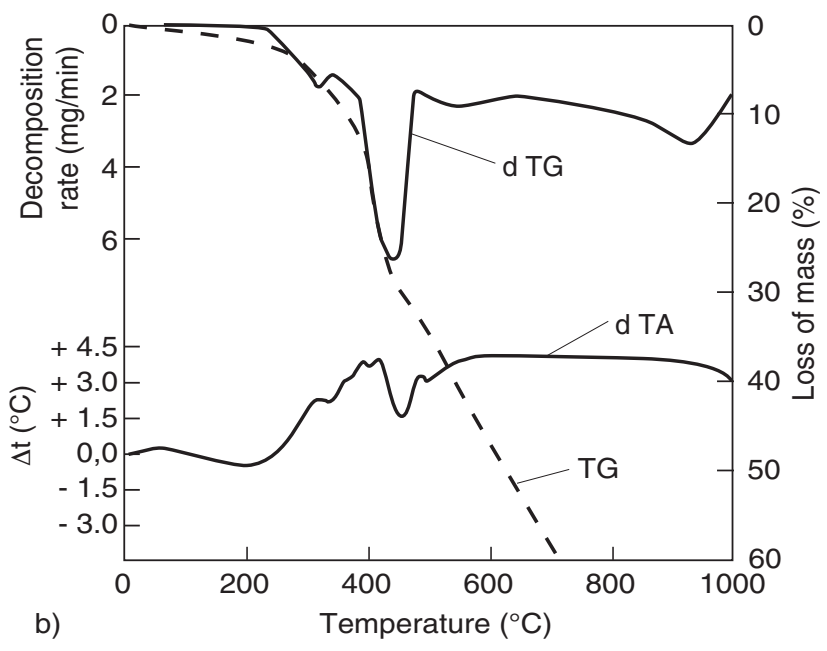

Figure 4

Results of thermogravimetric and differential thermal analysis of Rafaelita asphaltite in stationary inert conditions (a) and air (b).

Cracking leads to fast mass losses in temperature intervals of $320-480^{\circ} \mathrm{C}$ and, according to the maximum on $d \mathrm{TG}$ curves, reaches a maximal rate at $435-440^{\circ} \mathrm{C}$.

Mass loss continues in the temperature range from $500^{\circ} \mathrm{C}$ up to $700^{\circ} \mathrm{C}$, but with less speed, apparently, because of condensation reactions of aromatic rings. Loss in mass stops

The curve of thermal effects (dTA) has no significant maximums, but evident heat absorption begins at $300^{\circ} \mathrm{C}$.

The same decomposition processes were observed when asphaltites were heated in stationary air medium. But in this case, the rate of mass loss at temperatures above $400^{\circ} \mathrm{C}$ was higher than in helium, indicating the significant role of oxidation reactions (Fig. 3b).
The process of asphaltite decomposition occurs faster in air flow (Fig. 4b). If mass loss in stationary medium was equal to $60 \mathrm{wt} . \%$ at $700^{\circ} \mathrm{C}$, the same level of decomposition in air flow was reached at $420^{\circ} \mathrm{C}$.

Eventual mass loss of all asphaltite samples was not less than $95-96$ wt. $\%$ at temperatures approaching $1000^{\circ} \mathrm{C}$.

\subsection{Compositional and Structural Characteristics of Asphaltite Components}

The macrostructural characteristics of oil, resin and asphaltene fractions were estimated by the procedure [22] using the 
data of elementary analysis, molecular weights, $1 \mathrm{H}$ and 13CNMR. The following parameters were calculated:

$f_{p} \quad$ portion number of carbon atoms in paraffin fragments of molecules,

$f_{n} \quad$ portion number of carbon atoms in naphthenic fragments of molecules,

$m_{a} \quad$ number of structural units (blocks) in the average molecule,

$K_{o}^{*}$ total number of cycles,

$K_{a}^{*}$ number of aromatic cycles,

$K_{\text {sat }} *$ number of saturated (naphthenic) cycles,

$\mathrm{C}^{*}$ total number of $\mathrm{C}$-atoms in the average molecule,

$\mathrm{C}_{\mathrm{p}}{ }^{*}$ number of $\mathrm{C}$-atoms in alkyl moieties of the average molecule,

$\mathrm{C}_{\mathrm{a}}{ }^{*}$ number of $\mathrm{C}$-atoms in $\alpha$-position to aromatic nuclei and heterofunctional groups,

$\mathrm{C}_{\tilde{\mathrm{a}}}$ * number of $\mathrm{C}$-atoms in $\mathrm{CH}_{3}$-groups not connected with aromatic nuclei and heterofunctions,

$\sigma_{\mathrm{a}} \quad$ substitution degree of peripheral C-atoms of aromatic nuclei.

General concepts about the structure of asphaltite components give values of average molecular parameters of separated oily, resin and asphaltene + carbene $(\mathrm{A}+\mathrm{K})$ fractions (Table 2).

According to experimental data weakly adsorbing substances, that were eluted in boiling hexane from the Soxhlet extractor and are named here oils (hydrocarbons), actually turned out to be a concentrate of high-molecular compounds (resins), that possibly contain a small impurity of hydrocarbons.

If most molecules of asphaltite oils contain no more than one $\mathrm{S}$ - and $\mathrm{N}$-atom and one or two O-atoms, as is usual for similar petroleum components [19], according to the empirical formula of substances, these oils must consist of about 6 mol.\% nitrogenous, $58 \%$ sulfurous and $43-87 \%$ oxygen-containing compounds. The portion of hydrocarbon components in asphaltite oils does not exceed $7 \mathrm{~mol} . \%$.

Large particles with average molecular weight of 730 $\mathrm{g} / \mathrm{mol}$. and content of C-atoms of more than 50 in the composition of the "average molecule" were found in asphaltite oils. Existence of these particles may be explained by the high bent of heteroorganic compounds for intermolecular association.

According to the calculated data (Table 2), the oils consist of mono-block molecules $\left(m_{a}=1.0\right)$. These molecular blocks contain, on average, tetra- or pentacyclic structures built from $K_{a}{ }^{*}=2.6$ aromatic and $K_{n}{ }^{*}=2.8$ saturated rings. These rings, probably, are condensed into a single polycyclic system.

A distinctive feature of R-3 oily components is the presence of developed aliphatic fragments that contain $f_{p}=56 \%$ of all C-atoms and have $C_{p}{ }^{*}=29$ atoms in each average
TABLE 2

Average physical-chemical characteristics of soluble-in-chloroform asphaltite fractions

\begin{tabular}{c|c|c|c|c|c|c}
\hline Indices & \multicolumn{5}{c}{ Values for } \\
\hline & oils & resins & maltenes & $\mathrm{A}+\mathrm{K}$ & resins & $\mathrm{A}+\mathrm{K}$ \\
\hline & \multicolumn{5}{|c|}{ from R-03 sample } & \multicolumn{2}{c}{$\begin{array}{c}\text { from } \\
\text { T-05 sample }\end{array}$} \\
\hline Content, wt.\% of OMA & 4.2 & 18.6 & 22.8 & 56.8 & 5.2 & 30.8 \\
Mean molecular weight & 730 & 1250 & 1156 & 2285 & 645 & 1560 \\
\hline
\end{tabular}

Elemental composition, wt.\%

\begin{tabular}{l|c|c|c|c|c|c}
$\mathrm{C}$ & 84.23 & 82.37 & 82.70 & 84.83 & 79.40 & 82.87 \\
$\mathrm{H}$ & 11.19 & 10.45 & 10.58 & 7.43 & 9.95 & 9.71 \\
$\mathrm{~N}$ & 0.11 & 1.01 & 0.85 & 1.18 & 0.70 & 1.01 \\
$\mathrm{~S}$ & 2.56 & 2.44 & 2.46 & 2.19 & 4.76 & 2.68 \\
$\mathrm{O}$ & 1.91 & 3.82 & 3.48 & 4.37 & 5.19 & 3.74 \\
\hline
\end{tabular}

Number of atoms in "mean molecules"

\begin{tabular}{l|c|c|c|c|c|c}
$\mathrm{C}$ & 51.24 & 85.80 & 79.59 & 161.5 & 42.68 & 107.7 \\
$\mathrm{H}$ & 81.04 & 129.6 & 120.87 & 168.4 & 63.67 & 150.3 \\
$\mathrm{~N}$ & 0.06 & 0.91 & 0.76 & 1.93 & 0.32 & 1.13 \\
$\mathrm{~S}$ & 0.58 & 0.95 & 0.88 & 1.56 & 0.96 & 1.31 \\
$\mathrm{O}$ & 0.87 & 2.98 & 2.60 & 6.24 & 2.09 & 3.65 \\
\hline
\end{tabular}

\begin{tabular}{l|c|c|c|c|c|c} 
Atomic ratios & 1.582 & 1.510 & 1.519 & 1.043 & 1.492 & 1.396 \\
$\mathrm{H} / \mathrm{C}$ & 0.0012 & 0.0106 & 0.0088 & 0.0120 & 0.0075 & 0.0105 \\
$\mathrm{~N} / \mathrm{C}$ & 0.0113 & 0.0111 & 0.0111 & 0.0097 & 0.0225 & 0.0122 \\
$\mathrm{~S} / \mathrm{C}$ & 0.0170 & 0.0347 & 0.0327 & 0.0389 & 0.0490 & 0.0339 \\
$\mathrm{O} / \mathrm{C}$ &
\end{tabular}

Distribution of C-atoms, \%

\begin{tabular}{l|c|c|c|c|c|c}
$f_{a}$ & 23.9 & 30.0 & 28.9 & 44.1 & 25.0 & 30.5 \\
$f_{n}$ & 20.2 & 6.0 & 8.55 & 50.4 & 24.6 & 27.1 \\
$f_{p}$ & 55.9 & 64.0 & 62.54 & 5.5 & 50.4 & 42.4 \\
\hline
\end{tabular}

Ring composition

\begin{tabular}{l|l|l|l|l|l|l}
$K_{o}$ & 5.40 & 7.86 & 7.42 & 41.69 & 5.10 & 15.58 \\
$K_{a}$ & 2.60 & 6.21 & 5.56 & 17.07 & 2.23 & 8.03 \\
$K_{n}$ & 2.80 & 1.65 & 1.86 & 24.62 & 2.87 & 7.55 \\
\hline
\end{tabular}

Parameters of mean structural block

\begin{tabular}{l|c|c|c|c|c|c}
$\mathrm{m}_{\mathrm{a}}$ & 1.00 & 1.31 & 1.25 & 4.00 & 1.00 & 1.38 \\
$K_{o}^{*}$ & 5.40 & 6.00 & 5.94 & 10.42 & 5.10 & 11.29 \\
$K_{a}^{*}$ & 2.60 & 4.74 & 4.45 & 4.27 & 2.23 & 5.82 \\
$K_{n}^{*}$ & 2.80 & 1.26 & 1.49 & 6.15 & 2.87 & 5.47 \\
$\mathrm{C}^{*}$ & 51.24 & 65.50 & 62.94 & 40.38 & 42.68 & 78.07 \\
$\mathrm{C}_{a}^{*}$ & 12.25 & 19.65 & 16.11 & 17.81 & 10.67 & 23.81 \\
$\mathrm{C}_{\mathrm{n}}^{*}$ & 10.34 & 3.93 & 5.08 & 20.36 & 10.51 & 21.12 \\
$\mathrm{C}_{\mathrm{p}}{ }^{*}$ & 28.65 & 41.92 & 39.53 & 2.22 & 21.50 & 33.13 \\
$\mathrm{C}_{\alpha}{ }^{*}$ & 3.02 & 5.15 & 4.77 & 3.60 & 3.56 & 6.51 \\
$\mathrm{C}_{\gamma}^{*}$ & 6.65 & 6.44 & 6.48 & 2.22 & 4.10 & 5.77 \\
$\mathrm{~N}^{*}$ & 0.06 & 0.69 & 0.58 & 0.48 & 0.32 & 0.82 \\
$\mathrm{~S}^{*}$ & 0.58 & 0.72 & 0.69 & 0.39 & 0.96 & 0.95 \\
$\mathrm{O}^{*}$ & 0.87 & 2.27 & 2.02 & 1.56 & 2.09 & 2.64 \\
\hline
\end{tabular}


block. Only $C_{\gamma}{ }^{*}=6-7$ of them are in terminal methyl groups.

That suggests the presence of long linear or weakly branched alkyl chains in molecules. The significant predominance of C-atoms in saturated molecular fragments: $\left(f_{p}+f_{n}\right)$ $=76 \%$, compared with $f_{\mathrm{a}}=24 \%$ in aromatic ones, is the reason for the solubility of these substances in hexane and the possibility of being isolated as a separate oily fraction.

All $C_{a}$ carbon atoms, connected directly to aromatic nuclei, are located on the same plane as those aromatic nuclei. Besides, $C_{a}$ carbon atoms are found in the structure of batch compositions by $\mathrm{X}$-ray diffraction analysis. Taking into account these facts, it is significant to mention the good quantitative agreement between results obtained with the use of two independent methods: X-ray diffraction and magnetic resonance.

Resins from R-03 asphaltite samples have different structural features, in comparison with oily components. Not less than $70 \%$ of molecules of these substances consist of one molecular block. These blocks include tetra- and pentacyclic condensed aromatic nuclei in ratios of about 1:3 $\left(K_{a}^{*}=\right.$ $4.74)$, i.e. they are much larger than typical resins of oil genesis $[6,22]$.

$\mathrm{R}-03$ resins are poor in saturated cycles: with only one or two of them in an average structural unit. On the other hand, aliphatic structures (alkyl substitutes and inter-block bridges) are highly developed and accumulate $f_{p}=64 \%$ of all C-atoms in molecules or $C_{p}{ }^{*} \approx 42$ such atoms in an average structural unit. The number of methyl groups in the units is considerably smaller; that means that long linear or weakly branched aliphatic chains are contained in R-03 resin molecules just as in oily ones.

The biggest proportion of structural blocks in R-03 resin molecules are also heteroatomic; approximately $70 \%$ of them contain $\mathrm{N}$-atoms and the same number of them include sulfur $\left(\mathrm{N}^{*} \approx \mathrm{S}^{*} \approx 0.7\right)$. In addition, more than two oxygen atoms are contained in each average molecular block. These Oatoms may be as in arenofurane nuclei or in ester bridges that connect separate blocks.

Asphaltene and carbene components $(\mathrm{A}+\mathrm{K}$ fraction) of $\mathrm{R}-03$ samples (more than half of the R-03 mass) are proved to be the only fraction among soluble fractions in chloroform products that consist mainly of four-block molecules $\left(m_{a}=\right.$ 4.0). This parameter is quite similar to the number of layers in batches found by $\mathrm{X}$-ray diffraction analysis $(\mathrm{M}=4.4)$.

The calculated ring number in aromatic nuclei of average $\mathrm{A}+\mathrm{K}$ molecules is also similar to the value obtained for maltene components from the same source $\left(K_{a}^{*}=4.27\right.$ and 4.45 , respectively). In other words, tetra- and pentacyclic aromatic nuclei are most widely distributed in all the R-03 described fractions. X-ray analysis indicates the same.

However, maltene and $\mathrm{A}+\mathrm{K}$ components of $\mathrm{R}-03$ asphaltite differ significantly in structural characteristics of saturated molecular fragments. On the contrary to oils and resins, asphaltenes from R-03 are rich in naphthenic structures that accumulate a half of C-atoms in molecules $\left(f_{n}=\right.$ $50.4 \%$ ) and include $K_{n}{ }^{*}=6.15$ cycles for each aromatic nucleus. At the same time, aliphatic fragments of these substances contain only methyl groups connected with naphthenic C-atoms $\left(C_{p}{ }^{*}=C_{\gamma}{ }^{*}=2.2\right)$.

Asphaltite T-05 of the Toribia field differs from the R-03 samples described above both in common material composition (absence of oils, very small portion of resins and high content of carboids) and structural-group characteristics of isolated fractions.

According to the obtained data resin components of T-05 samples consist only of mono-block molecules, which are smaller than R-03 resin molecules. T-05 resins have an average molecular weight of only 645 (against 1250 for R-03) and contain only $42.8 \mathrm{C}$-atoms instead of 65.5 (R-03).

Molecules of T-05 resins are proved to be mainly pentacyclic and have 2.2 aromatic and 2.9 naphthenic rings. Almost one-third of these molecules contain N-atoms, $96 \%$ of them are sulfurous and almost all of them include some oxygen group.

Aliphatic molecular fragments contain 21.5 C-atoms on average. In other words, resin components of T-05 asphaltite have two-fold smaller dimensions of aromatic and paraffin molecular fragments. What is more, T-05 resin components have a considerably greater development of the naphthenic structure compared with R-03.

At the same time, it should be noted that all the mentioned structural parameters of the carbon system of T-05 resin molecules are similar to corresponding characteristics of the oily fraction of R-03 asphaltite. The most noticeable differences between these two resins, such as different concentrations of heteroelements and paraffin C-atoms, caused an increase in the ability of T-05 resins to adsorb on the silica gel and inability to elute with hexane under conditions of separation in a Soxhlet apparatus.

The $(\mathrm{A}+\mathrm{K})$ fraction of T-05 asphaltite consists of monoand two-block molecules in a ratio of about 2:1 $\left(m_{a}=1.38\right)$. That $\mathrm{T}-05$ fraction differs substantially from the similar fraction of R-03, that is formed by considerably larger poly-block particles.

The most common structures of aromatic nuclei in the $(\mathrm{A}+\mathrm{K})$ fraction of T-05 have five or more condensed benzene rings. Not less than $80 \%$ of these nuclei are hexacyclic $\left(K_{a}^{*}=5.82\right)$. Both $(\mathrm{A}+\mathrm{K})$ fractions of $\mathrm{T}-05$ and $\mathrm{R}-03$ have similar highly developed naphthenic structures. Unlike R-03 asphaltenes, that contain basically only methyl groups, every structural block of T-05 asphaltene molecules has long aliphatic chains $\left(C_{p}{ }^{*}=33.1\right.$ while $C_{\gamma}{ }^{*}$ is only 5.8 atoms $)$.

We could not measure molecular weights and obtain NMR spectra of carboid components of asphaltites because of their inability to dissolve in all commonly used solvents 
except carbon disulfide. Therefore, these substances are characterized here only by their elemental composition (Table 3). Balance calculations based on these data showed that carboids accumulate $64 \%$ and even $86 \%$ of S-atoms in R- 03 and $\mathrm{T}-05$, respectively.

TABLE 3

Elemental composition of carboids

\begin{tabular}{l|c|c}
\hline \multirow{2}{*}{\multicolumn{1}{c|}{ Indices }} & \multicolumn{2}{c}{ Values for components of } \\
\cline { 2 - 3 } & R-03 & T-05 \\
\hline $\begin{array}{l}\text { Yield from asphaltite, wt.\% } \\
\text { Content, wt.\% of }\end{array}$ & 20.4 & 64.0 \\
\hline C & 76.73 & 76.43 \\
H & 7.14 & 7.60 \\
N & 1.12 & 1.50 \\
S & 12.86 & 10.23 \\
O & 3.79 & 4.32 \\
\hline Atomic ratios & & \\
H/C & 1.108 & 1.184 \\
N/C & 0.0125 & 0.0168 \\
S/C & 0.0627 & 0.0501 \\
O/C & 0.0370 & 0.0424 \\
\hline
\end{tabular}

The relative hydrogen content of carboids $-110-118 \mathrm{H}-$ atoms for $100 \mathrm{C}$-atoms - in most cases is lower than in other asphaltite fractions. But it is significantly higher than hydrogen content in not-substituted condensed aromatic compounds, whose hydrogen content decreases with an increase in the number of rings in molecules (from $80 \mathrm{H}$-atoms in naphthaline to 63.6 in pycene, counting on 100 carbon atoms).

This means that carboids, just like other asphaltite fractions, contain well-developed saturated structures. That accords with X-ray diffraction data, which shows that such spatially not organized structures include about $60 \%$ of Catoms in the composition of these asphaltites.

\subsection{Thermal Decomposition of R-03 Asphaltite Samples}

Gaseous product (pyrogas) as well as liquid gasoline and diesel distillates were obtained with yields of 20, 14 and 21 wt.\% (on initial raw material), respectively, when solid R-03 asphaltite samples were pyrolyzed (Tables 4 and 5).

According to chromatographic data, gaseous products of asphaltite pyrolysis are comparatively rich in hydrogen sulfide because of the presence of significant amounts of thioethers in the initial stock. These products include all isomeric alkanes and olefins from methane to $\mathrm{C}_{5}$-hydrocarbons. Those products were produced by destruction of alkyl substitutes present in R-03 in sufficiently large amounts. The
TABLE 4

Characteristics of gaseous products of pyrolysis

\begin{tabular}{l|c|c|c}
\hline \multicolumn{1}{c|}{ Indices } & Values & Indices & Values \\
\hline Yield, wt.\%20.1 & & Content, wt.\% of & \\
\hline Density, $\mathrm{kg} / \mathrm{m}^{3}$ & 0.9703 & ethylene & 2.0 \\
\hline Density relative to air & 0.8570 & propane & 23.0 \\
\hline Mean molecular weight & 24.84 & propylene & 1.2 \\
\hline Content, wt.\% of & & isobutane & 1.6 \\
\hline hydrogen & 2.5 & $n$-butane & 19.2 \\
\hline carbon dioxide & 0.4 & C4-olefins & 2.7 \\
\hline hydrogen sulfide & 4.5 & isopentane & 2.5 \\
\hline methane & 14.2 & n-pentane & 2.5 \\
\hline ethane & 17.2 & $\mathrm{C}_{5}$-olefins & 6.5 \\
\hline
\end{tabular}

TABLE 5

Characteristics of liquid pyrolysis products

\begin{tabular}{l|c|c}
\hline \multirow{2}{*}{ Indices } & \multicolumn{2}{c}{ Values for } \\
\cline { 2 - 3 } & gasoline fraction & diesel fraction \\
\hline Yield, wt.\% & 14.0 & 21.0 \\
\hline Density at $20^{\circ} \mathrm{C}, \mathrm{kg} / \mathrm{m}^{3}$ & 777.4 & 897.9 \\
\hline Mean molecular weight & 110 & 203 \\
\hline Kinematic viscosity, $\mathrm{cm}^{2} . \mathrm{c}$ & - & 75.4 \\
\hline $\begin{array}{l}\text { Content of sulfur, wt.\% } \\
\text { total } \\
\text { mercaptanic }\end{array}$ & 4.94 & 2.18 \\
\hline Number of S-atoms in "mean molecule" & 0.04 & 0.012 \\
\hline Cooking ability by Conradson, wt.\% & - & 0.14 \\
\hline Color by ASTM D 1500, conv. units & 4 & 3.13 \\
\hline
\end{tabular}

formation of isoalkanes indicates the presence of branched aliphatic fragments in asphaltite molecules.

High concentration of sulfur is also characteristic for liquid pyrolysis products (5 wt. $\%$ for gasoline and $2.2 \mathrm{wt} . \%$ for diesel). These products have a dark color and too high viscosity and coking behavior to be used as motor fuels without additional refining.

A wide series of experiments on thermal decomposition of the same asphaltites in the presence of different solvents were also done. The earliest of these experiments were performed by techniques similar to ones used earlier for liquefaction of brown coal $[23,24]$. As great as $73.7 \%$ of OMA conversion degree was reached when the final temperature of the asphaltite liquefaction process was $450^{\circ} \mathrm{C}$, i.e. OMA conversion was lower than in similar coal processing [15]. 
It is important that $95 \mathrm{wt} . \%$ of liquid products of asphaltite liquefaction (70\% of its total organic mass) were oils and only 5\% resin-asphaltene substances. It should be mentioned that the lasts were, on the contrary, the main products (58\%) of brown coal liquefaction.

These experiments showed that about $70 \%$ of asphaltite organic mass may be converted into valuable liquid hydrocarbon products compared with $30 \%$ in the process of brown coal liquefaction under the same operational conditions [15].

The influence of different solvents, added to asphaltite samples during the process of liquefaction under isothermal conditions, was studied in another series of experiments. Ndecane, tetraline and water were tested as solvents (Table 6). It was shown earlier that the conversion degree of heavy petroleum residua and coal products, which are also rich in resin-asphaltic components, in the process of thermal decomposition in the medium of vaporized water may be substantially improved by addition of iron oxides as catalyst [26, 27]. Therefore, hematite was added to the reaction mixture in some asphaltite liquefaction experiments.

TABLE 6

Parameters of the asphaltite liquefaction process at $350^{\circ} \mathrm{C}$ in the presence of different solvents and hematite addition

\begin{tabular}{|c|c|c|c|c|}
\hline \multirow{2}{*}{$\begin{array}{l}\text { Reaction } \\
\text { medium }\end{array}$} & \multicolumn{3}{|c|}{ Yield, wt.\% of OMA, of } & \multirow{2}{*}{$\begin{array}{c}\text { Total } \\
\text { conversion }\end{array}$} \\
\hline & oils & resins & $A+K$ fraction & \\
\hline
\end{tabular}

Asphaltite of Rafaelite field ( $R-03$ sample)

\begin{tabular}{l|c|c|c|c} 
Decane & 12.4 & 24.3 & 20.5 & 57.2 \\
\hline Tetraline & 5.8 & 15.2 & 36.2 & 57.2 \\
\hline Water & 11.9 & 11.2 & 28.2 & 51.3 \\
\hline Tetraline + water + hematite & 5.8 & 23.4 & 58.7 & 87.9 \\
\hline
\end{tabular}

Asphaltite of Toribia field (T-05 sample)

\begin{tabular}{l|c|c|c|c} 
Tetraline & 11.3 & 16.2 & 32.9 & 60.4 \\
\hline Water & 5.9 & 10.9 & 39.0 & 55.8 \\
\hline Tetraline + water + hematite & 5.0 & 7.2 & 77.4 & 89.6 \\
\hline
\end{tabular}

The total conversion degree of asphaltites in both hydrocarbon solvents (decane and tetraline) was similar (about 57-60\%), though the material compositions of the products differ substantially. When carrying out the process in tetraline - the typical proton-donor solvent widely used in coal liquefaction - $(\mathrm{A}+\mathrm{K})$ substances were obtained from both asphaltite samples with larger yields equal to 33-36 wt.\% (63-70\% of the sum of reaction products); another $15-16 \%$ of raw components were converted into resins and only 6$11 \%$ into oily products.

The yield of $\mathrm{A}+\mathrm{K}$ substances decreased significantly (20\% against $36 \%$ in tetraline) and yields of oily fractions and resins increased when $n$-decane was used instead of tetraline. This indicates that decane takes part in chain reac- tions of thermal destruction. Naturally, connection of aliphatic radicals of decane, generated by cracking, with molecules of asphaltite and its decomposition products must decrease the aromatic degree and increase solubility of the formed compounds in hexane, i.e. increasing maltenes' yields.

When asphaltites were thermolyzed in water medium, the total conversion degree decreased. Yields of resins became smaller. Yield of R-03 oils doubled when yield of $\mathrm{A}+\mathrm{K}$ products halved. While, for $\mathrm{T}-05$, yield of $\mathrm{A}+\mathrm{K}$ products doubled and yield of oils halved.

The reason for this difference in behavior of asphaltites seems to be caused by the presence of elemental sulfur (1.8 wt.\%) in T-05 asphaltite and its absence in R-03. The ability of sulfur to interact at high temperatures with hydrocarbons, leading to sewing of molecules and formation of high-molecular products, is widely used in techniques, for example, to produce lubricating liquids and vulcanize caoutchoucs into rubbers. Dehydrogenization properties of sulfur in hydrocarbon media are also well known. Dehydroaromatization of saturated cycles, especially joined directly with aromatic rings, in the presence of elemental sulfur results in enlargement of polycyclic aromatic nuclei and, as a result, yield of $\mathrm{A}+\mathrm{K}$ products increases.

Addition of hematite to the reaction mixture results in an increase in the total conversion degree of asphaltites up to $87-90$ wt.\% only in A + K substances. These content reaction products reached up to $67 \mathrm{wt} . \%$ in R-03 processing and 86 wt.\% in the case of T-05 samples. Yields of oily fractions diminished to such little values as 6-7 wt.\%. This effect is obviously caused by catalytic activity of iron oxides in reactions of dealkylation in aromatic nuclei [811]. Tearing saturated substitutes off, undoubtedly, facilitates stacking these nuclei into lamellar batches, formation of which is a distinctive feature of asphaltenes [10, 27]. As a result, the solubility of substances in aliphatic hydrocarbons is lowered, providing transformation of maltenic components into asphaltenes.

Under the described thermolysis conditions in water medium a much larger degree of asphaltite conversion was reached than by its maintenance at $350^{\circ} \mathrm{C}$ for one hour (78.8 wt.\% instead of $51.3 \%$, Tables 3, 4). Water eluted very small amounts (only $0.2 \mathrm{wt} . \%$ of feed stock) of organic matter if the temperature in the reaction zone was lower than $100^{\circ} \mathrm{C}$. At higher temperatures yields of eluates rise rapidly, the portion of oily substances in their composition decreases noticeably and average molecular weights of eluting compounds increase.

Yields of reaction products begin to increase at temperatures of $200-300^{\circ} \mathrm{C}$, that are still insufficient to rupture C-C bonds. Only breaking C-S saturated bonds may cause destruction of asphaltite macromolecules. The rate of this process becomes noticeable at $110-120^{\circ} \mathrm{C}$ [27]. 
TABLE 7

Characteristics of R-03 asphaltite liquefaction products under flow conditions of its processing

\begin{tabular}{l|c|c|c|c|c}
\hline $\begin{array}{c}\text { Interval } \\
\text { of reaction } \\
\text { temperatures, }{ }^{\circ} \mathrm{C}\end{array}$ & $\begin{array}{c}\text { Yield, } \\
\text { wt.\% }\end{array}$ & $\begin{array}{c}\text { Average } \\
\text { molecular } \\
\text { weight }\end{array}$ & \multicolumn{3}{|c}{ Content, wt.\% of } \\
\hline & & & oils & resins & A + K fraction \\
\hline $\begin{array}{c}\text { Elution with water } \\
\text { 20-100 }\end{array}$ & 0.19 & - & - & - & - \\
\hline $100-200$ & 1.35 & 990 & 32.5 & 12.0 & 55.5 \\
\hline $200-300$ & 8.70 & 1280 & 26.2 & 15.6 & 58.2 \\
\hline $300-400$ & 17.36 & 1360 & 22.4 & 19.6 & 58.0 \\
\hline $400-450$ & 22.63 & 815 & 21.3 & 25.8 & 52.9 \\
\hline $450-500$ & 28.53 & 530 & 23.0 & 22.5 & 54.5 \\
\hline Total 20-500 & 78.76 & 845 & 24.4 & 21.3 & 54.3 \\
\hline Elution with n-decane & 10.53 & 740 & 13.1 & 73.8 & 13.1 \\
\hline $20-100$ & 8.17 & 1470 & 15.8 & 55.0 & 29.2 \\
\hline $100-200$ & 8.25 & 1340 & 22.4 & 48.6 & 29.0 \\
\hline $200-300$ & 9.72 & 1245 & 30.4 & 36.6 & 33.0 \\
\hline $300-400$ & 11.37 & 575 & 42.6 & 28.3 & 29.1 \\
\hline $400-450$ & 25.84 & 505 & 59.4 & 22.9 & 17.7 \\
\hline $450-500$ & 73.88 & 770 & 24.2 & 45.6 & 29.3 \\
\hline Total 20-500 & & & & & \\
\hline & & & & \\
\hline
\end{tabular}

Yields of decomposition products rise especially when the reaction temperature exceeds $300^{\circ} \mathrm{C}$ and cracking of molecular saturated fragments develops. At higher temperatures formation of more than $90 \%$ of decomposition products is observed. More than half of them are produced in the interval of $400-500^{\circ} \mathrm{C}$. Mainly oily compounds are produced at temperatures exceeding $400^{\circ} \mathrm{C}$ : their portion in the sum of reaction products becomes six-fold larger than the native oil content of oils in the initial fossil. The material composition of mixtures formed at these high temperatures is relatively permanent, including 21-23 wt.\% of oils, $20-26 \%$ of resins and $53-58 \%$ of $\mathrm{A}+\mathrm{K}$ substances, i.e. the proportions of resins and $\mathrm{A}+\mathrm{K}$ fractions remain almost the same as in the original asphaltite.

Another pattern is observed when asphaltite is processed under flow conditions using decane as eluent. In this case, the total conversion degree of asphaltite is smaller compared with processing in water medium. The ability of decane to dissolve maltenes is still found at lower temperatures, because about $10 \mathrm{wt} . \%$ of asphaltite was eliminated from the reaction zone at temperatures below $100^{\circ} \mathrm{C}$ (Table 7).

Resin substances present almost three-quarters of these low-temperature decane eluates. An increase in quantities of matter eluting under such conditions becomes noticeable at temperatures higher than $300^{\circ} \mathrm{C}$. High reaction temperatures caused an increase in the oil portion among forming products and corresponding to both resins and $\mathrm{A}+\mathrm{K}$ substances. Towards the end of the liquefaction process, in temperature intervals of $450-500^{\circ} \mathrm{C}$, a mixture containing almost $60 \mathrm{wt} . \%$ of oils and less than $18 \%$ of $\mathrm{A}+\mathrm{K}$ components was formed.

The total yield of oils produced in this experiment was practically the same compared with liquefaction in water. But the portion of resins increased in this case more than two-fold (up to $46 \%$ ) and quantities of asphaltenes and carbenes also diminished almost two-fold (down to 29\%). Effects of alkylation by radicals that are generated by destruction of solvent molecules, in asphaltite liquefaction in stationary decane medium, most obviously, play a similarly important role when stock processing at flow regime.

\section{CONCLUSIONS}

Our experiments showed that thermal liquefaction of asphaltites should be carried out in medium of hydrogendonor solvent at temperatures not lower than $400-450^{\circ} \mathrm{C}$, with permanently eliminated destruction products from the reaction zone. Under such conditions the maximal efficiency of the process was observed, i.e. the largest yields of the most valuable hydrocarbon oils. In these circumstances, about $70 \%$ of asphaltite organic mass may be transformed into soluble maltenic substances, including up to $25 \%$ into oily ones, if $n$-alkanes are used as solvents. Yield of oils may be increased by up to $70 \%$ when real petroleum distillate (diesel) is used, as a medium rich in branched and cyclic hydrocarbons is more predisposed to generate radicals and, hence, to take part in chain destruction reactions of asphaltite components.

Addition of an oxide catalyst (hematite) into the reaction medium increases the conversion degree of asphaltites. But only asphaltenes that are not valuable and carbenes were obtained, that are inexpedient.

\section{REFERENCES}

1 Hanson W. (1964) Nomenclature and terms bituminous materials: asphalts, tars, and pitches. Encyclopedia of Chemical Technol. 14, 1-24.

2 Oztas N.A., Yurum Y. (2000) Pirolysis of Turkish bituminous coal. Part 1. Effect of mi-Teral matter, Fuel 79, 10, 1221-1227.

3 Curiale J.A. (1991) The petroleum geochemistry of Canadian Beaufort Tertiary «non-marine» oils, Chem. Geology 93, 21-45.

4 Collin G., Mildenberg R. (1978) Coal tar chemistry - today and tomorrow, Chem. Ind. 5, 567-571.

5 Bogomolov A.I., Temyanko M.B., Khotyntseva L.I. (1984) Sovremennyye metody issledovaniya neftei (Modern methods of petroleum investigations), Nedra, Leningrad. 
6 Kamyanov V.F., Filimonova T.A., Gorbunova L.V. et al. (1988) Neftyanyye smoly i asfal'teny (Petroleum resins and asphaltenes), in Khimicheskiy sostav neftei Zapadnoy Sibiri (Chemical composition of west-Siberian crude oils), Nauka, Novosibirsk.

7 Patrakov Yu.F., Denisov S.V., Kamyanov V.V. et al. (2001) Strukturno-gruppovoy analiz vysokomolekulyarnyh produktov termicheskogo rastvoreniya barzaskogo liptobiolitovogo uglya, Himiya tverdogo topliva (Rus) 1, 67-73.

8 Houben W. (1953) Methoden der organischen chemie. Book II. Analytishe methoden, Verlag Georg Tieme, Stuttgart.

9 Klimova V.A. (1975) Osnovnyye mikrometody analyza organicheskikh soedineniy (Principal micromethods of organic compounds' analysis), Khimia, Moscow.

10 Kamyanov V.F., Bodraya N.V., Sivirilov P.P. et al. (1989) Rentgenodifraktsionnyy analiz smolisto-asfal'tenovyh komponentov zapadnosibirskoy nefti, Neftehimiya (Rus) 29, 1, 3-13.

11 Sharypov V.I., Kuznetsov B.N., Beregovtsova N.G. et al. (1996) Steam cracking of coal-derived liquids and some aromatic compounds in the presence of haematite, Fuel 75, 7, 791-802.

12 Eglinton T.I., Rowland S.J. (1986) Kerogen-mineral reactions at raised temperatures in the presence of water, Adv. Organic Geochem. 5, 1041-1052.

13 Neavel R.C. (1976) Liquefaction of coal in hydrogen-donor and non-donor vehicles, Fuel 55, 7, 237-242.

14 Silverstein R.M., Bassler C.G., Morril T.C. (1974) Spectrometric identification of Organic Compounds, John Wiley and Sons, New York.

15 Shadle L.J., Neill P.H., Given P.H. (1988) Dependence of liquefaction behavior on coal characteristics of a set of high sulphur coals and asphaltenes, Fuel 67, 11, 1465-1467.

16 Kitaygorodskiy A.I., Zorkiy P.M., Bel'skiy V.K. (1980) Stroenie organicheskogo veschestva: Dannye strukturnyh issledovaniy, Nauka, Moscow.

17 Jdanov G.S., Ilyushin A.S., Nikitina S.V. (1980) Difraktsionnyy $i$ rezonansnyy strukturnyy analiz, Nauka, Novosibirsk.
18 Patrakov Yu.F., Kamyanov V.F., Fedyaeva O.N. (2005) A structural model of the organic matter of Barsas liptobioliht coal, Fuel 84, 2-3, 189-195.

19 Kamyanov V.F., Aksenov V.S., Titov V.I. (1983) Geteroatomnyye komponenty neftey (Heteroatomiñ petroleum components), Nauka, Novosibirsk.

20 Valcovic V., Makjanic Ja., Jaksic M. et al. (1984) Analysis of fly ach by X-ray emission spectroscopy and proton microbeam analysis, Fuel 63, 10, 1357-1362.

21 Kamyanov V.F., Gorbunova L.V., Shabotkin I.G. (1996) Osnovnye zakonomernosti v sostave i stroenii vysokomolekulyarnyh komponentov tyajelyh neftey i prirodnyh bitumov. Neftehimiya (Rus) 1, 3-11.

22 Kamyanov V.F., Bolshakov G.F. (1984) Opredelenie strukturnyh parametrov pri strukturno-gruppovom analize komponentov nefti, Neftehimiya (Rus) 4, 450-459.

23 Patrakov Yu.F., Denisov S.V. (1988) Vybor metodiki dlya izucheniya kinetiki ojijeniya barzasskogo sapromiksita $\mathrm{v}$ neizotermicheskih usloviyah, Himiya tverdogo topliva (Rus) $\mathbf{3}$, 134-136.

24 Patrakov Yu.F., Denisov S.V., Ochirjapova O.D. (1991) Kineticheskiy analiz protsessa termicheskogorastvoreniya barzasskogo uglya, Himiya tverdogo topliva (Rus) 1, 103-110.

25 Yochimoto I., Itoh H., Makabe M., Ouchi K. (1984) Pressure and temperature effects on the hydrogenation of coal-derived asphaltene, Fuel 63, 7, 978-987.

26 Sharypov V.I., Beregovtsova N.G., Baryshnikov S.V., Kuznetsov B.N. (1997) Piroliz neftyanogo ostatka i nekotoryh organicheskih soedineniy $\mathrm{v}$ srede vodyanogo para v prisutstvii gematita, Himiya $v$ interesah ustoychivogo razvitiya (Rus) $\mathbf{5}$, 287-194.

27 Obolentsev R.D., Baykova A.Ya. (1973) Seraorganicheskie soedineniya neftey Uralo-Povolj'ya i Sibiri, Nauka, Moscow.

Final manuscript received in September 2007 